\title{
Statistical illiteracy undermines informed shared decision making
}

\author{
Wolfgang Gaissmaier*, Gerd Gigerenzer \\ Max Planck Institute for Human Development, Harding Center for Risk Literacy, Berlin
}

\section{Summary}

Shared decision making relies on the exchange of information between the physician and the patient and the involvement of both patient and physician in making the decision. Informed shared decision making thus requires that patients and doctors understand the benefits and harms of different treatment options. This, however, is severely undermined by what we call collective statistical illiteracy. Both patients and physicians have difficulties to understand the meaning of numbers so that an effective risk communication cannot take place. Risk communication based on misunderstandings, however, renders the "informed" in informed shared decision making obsolete. We show that the problem of statistical illiteracy can largely be solved by changing the representation of statistical information. Insight can be achieved by communicating risks in absolute, not relative terms; by using a frequentist formulation, which makes the reference class clear instead of communicating single event probabilities; and by communicating natural frequencies instead of conditional probabilities.

Key words: informed shared decision making, statistical illiteracy, risk communication, transparent representation

\section{Mangelndes Statistikverständnis untergräbt die informierte partizipative Entscheidungsfindung}

\section{Zusammenfassung}

Partizipative Entscheidungsfindung beruht auf dem Austausch von Informationen zwischen Arzt und Patient und der Beteiligung beider an der Entscheidungsfindung. Eine informierte partizipative Entscheidungsfindung erfordert daher, dass Patienten und Ärzte sich über die Vor- und Nachteile der verschiedenen Behandlungsoptionen im Klaren sind. Stark untergraben wird diese allerdings durch kollektiv mangelndes Statistikverständnis. Sowohl Patienten als auch Ärzte tun sich schwer damit, die Bedeutung von Zahlen zu verstehen, so dass keine effektive Risikokommunikation stattfinden kann. Eine auf Missverständnissen beruhende
Risikokommunikation jedoch macht das "informiert” in dem Begriff "informierte, partizipative Entscheidungsfindung" hinfällig. Wir zeigen, dass sich das Problem mangelnden Statistikverständnisses durch eine geänderte Darstellung statistischer Informationen weitgehend beheben lässt. Einsicht entsteht indem Risiken absolut statt relativ dargestellt werden, indem eine frequentistische Formulierung benutzt wird, die die Referenzklasse klar macht anstatt Einzelfall-Wahrscheinlichkeiten anzugeben, und indem man natürliche Häufigkeiten anstelle von bedingten Wahrscheinlichkeiten kommuniziert.

Schlüsselwörter: Informierte partizipative Entscheidungsfindung, mangelndes Statistikverständnis, Risikokommunikation, transparente Darstellung

\footnotetext{
*Corresponding author. Wolfgang Gaissmaier, Harding Center for Risk Literacy, Max Planck Institute for Human Development, Königin-Luise Str. 5, 14195 Berlin. E-Mail: gaissmaier@mpib-berlin.mpg.de (W. Gaissmaier).
} 
Imagine that a woman discusses the risks of taking the contraceptive pill with her doctor, and the doctor tells her that the third generation of contraceptive pills double the risk of potentially life-threatening blood clots in the legs or lungs. That is, they increase the risk by $100 \%$. Should this woman decide to take the pill nevertheless? Many women in the UK decided not to take this pill anymore when in October 1995 the UK Committee on Safety of Medicines issued such a warning about this risk. This 'pill scare' led to an estimated 13,000 additional abortions in the following year, increasing the cost for the National Health Service for abortion provision by about $\mathrm{f} 46$ million [1].

But what does the increase by $100 \%$ actually mean? The studies on which the warning was based had shown that of every 7,000 women who took the earlier, second-generation oral contraceptive pills, about 1 had a thrombosis; this number increased to 2 among women who took third-generation pills. That is, the absolute risk increase was only 1 in 7,000, whereas the relative increase was indeed $100 \%$. Absolute risks are typically small numbers while the corresponding relative changes tend to look big - particularly when the base rate is low. Had the committee and the media reported the absolute risks, few women would have panicked and stopped taking the pill.

\section{Collective Statistical Illiteracy}

This example illustrates a larger societal problem, the problem of statistical illiteracy. People have difficulties to understand the meaning of numbers; they lack a skill called numeracy, analogous to the term literacy that refers to reading and writing. For instance, in a sample of female veterans in New England, 80\% were unable to convert 1 in 1,000 to $0.1 \%$ [2]. And those who had a higher inability in numeracy had more difficulties in interpreting important health statistics about the benefits of mammography screening. Lipkus, Samsa, and Rimer [3] demonstrated that this problem of low numeracy generalizes to a larger population of rather well-educated citizens. And although physicians do significantly better on the task of converting 1 in 1,000 to $0.1 \%$, even among them, $25 \%$ get this basic computation wrong [4].

This becomes worse when interpreting more complicated health statistics, such as understanding relative risks (as in the pill scare example above). The problem with relative risks is that they remain silent about the baseline risk, while the absolute risk makes this transparent. A 100\% risk increase could mean an increase from 1 to 2 out every 7,000 women, as in the example above. However, it could also mean an increase from 1,000 to 2,000 out of every 7,000 women, which would be much more threatening. In particular for low probability risks, communicating changes in relative terms makes those changes loom larger than they actually are. This does not only hold for risk increases, but also for risk reductions. For instance, the benefits of mammography screening are usually communicated as a $25 \%$ reduction of the risk of dying from breast cancer [4]. In fact, this relative risk reduction approximately means that instead of 4 out of every 1,000 women, only 3 out of every 1,000 women die from breast cancer. The absolute risk reduction thus is 1 in 1,000 . A review of experimental studies showed that many patients, but also health professionals and physicians, do not understand the difference between relative and absolute risks and evaluate a treatment alternative more favorably if benefits are communicated as relative risk reductions [5].

Similar confusions can be observed when people have to interpret single event probabilities, such as when your doctor tells you that the risk of having sexual problems as a side effect is $30 \%$. The problem is that the reference class of these $30 \%$ is unclear. Many patients were frightened by such a statement, because they believed that it meant that every patient would have problems in about $30 \%$ of their sexual encounters. However, the statement actually meant that out of 100 patients, about 30 will occasionally experience a sexual problem. This frequentistic formulation makes the reference clear and made the statement less frightening to patients [6].

Another typical confusion usually happens when patients want to know what a positive test result actually means for them. Imagine that a patient participates in screening for colorectal cancer with the fecal occult blood test (FOBT) and receives a positive test result. Does that mean that this patient has cancer or not, or with which probability?

Hoffrage and Gigerenzer [7] tested 48 experienced physicians on this and other problems. One half was given the relevant information in conditional probabilities. That is, they were informed that the probability of positive test result given that a person has cancer (the sensitivity) was $50 \%$, that the false positive rate was $3 \%$, and that the prevalence of the disease was $0.3 \%$. The physicians were then asked to estimate the probability of colorectal cancer given a positive test result. Demonstrating that they were largely confused, their estimates ranged between a 1\% and a $99 \%$ chance of cancer. The most common mistake was that doctors believed that the statistic in question (the probability of cancer given a positive test result) was the same as the sensitivity (the probability of a positive test result given cancer), which is, of course, not the same. This can be illustrated with a more intuitive example. Up to 2008, every American and German president was male. That is, the probability of being male given that one is president was $100 \%$. The reverse, obviously, does not hold: Given that one is male, chances of being or becoming president are still rather low. The other half of the physicians in the study received the information in natural frequencies rather than conditional probabilities, and the confusion largely disappeared. The information was presented as follows: 30 out of every 10,000 people have colorectal cancer. Of these 30, 15 will have a positive FOBT result. Of the remaining people without cancer, 300 will nonetheless 
test positive. To compute the probability of cancer given the positive test result, one then simply needs to divide the number of correct positives (15) by the sum of correct and false positives $(15+300)$, which is about $4.8 \%$. With natural frequencies, most doctors got the answer right. Thus, the problem is not so much in physicians' minds but in an inadequate external representation of information, which is commonly used in medicine.

\section{Informed Shared Decision Making Rendered Obsolete}

In World Brain [8], H.G. Wells predicted that for an educated citizenship in a modern democracy, statistical thinking would be as indispensable as reading and writing. At the beginning of the $21^{\text {st }}$ century, nearly everyone in industrial societies has been taught reading and writing, but not statistical thinking, as these examples illustrate. This poses an existential obstacle to the ideal of informed shared decision making.

Shared decision making relies on the exchange of information between the physician and the patient and the involvement of both patient and physician in making the decision [9]. Informed shared decision making thus requires that patients and doctors understand the benefits and harms of different treatment options.

As summarized above, even with good will, some doctors would not be able to inform their patients adequately without two essential skills: understanding health statistics and communicating these in a transparent form. If both patients and physicians do not have minimal literacy in health statistics, an effective risk communication cannot take place. A risk communication based on misunderstandings, however, renders the "informed" in informed shared decision making obsolete.

It has been debated whether statistical illiteracy is mainly a consequence of cognitive limitations. However, such an internal attribution of the causes has not led to successful treatment. If "probability blindness" were caused by our cognitive limitations, then we just would have to live with it, or, as some have suggested, would have to keep citizens away from important decisions. In contrast to this view, we propose that this problem could largely be solved by changing the representation. The examples above illustrate that insight can be achieved by communicating risks in absolute, not relative terms; by using a frequentist formulation, which makes the reference class clear instead of communicating single event probabilities; and by communicating natural frequencies instead of conditional probabilities.

However, as long as the goal of some politicians and organizations rather is to persuade citizens to do what those politicians or organizations believe is right instead of informing them, changing the problem of communication top-down may stay a dream, even if it is a dream we continue working on. Additionally, we probably need pressure bottom-up: From patients who request their right of being informed in an understandable way and from doc- tors who believe it is the right thing to do to inform patients adequately and let them decide according to their values. This would be a crucial step towards the Enlightenment ideal of people's emergence from their selfimposed immaturity.

\section{References}

[1] Furedi A. The public health implications of the 1995 'pill scare'. Hum Reprod Update 1999;5(6):621-6.

[2] Schwartz LM, Woloshin S, Black WC, Welch $H G$. The role of numeracy in understanding the benefit of screening mammography. Ann Intern Med 1997;127(11):966-72.

[3] Lipkus IM, Samsa G, Rimer BK. General performance on a numeracy scale among highly educated samples. Med Decis Making 2001;21(1):37-44.

[4] Gigerenzer G, Gaissmaier W, Kurz-Milcke E, Schwartz LM, Woloshin S. Helping Doctors and Patients Make Sense of Health Statistics. Psychological Science in the Public Interest 2008;8(2):53-96.

[5] Covey J. A meta-analysis of the effects of presenting treatment benefits in different formats. Med Decis Making 2007;27(5): 638-54.

[6] Gigerenzer G. Calculated risks: How to know when numbers deceive you. UK edition: Reckoning with risk: Learning to live with uncertainty. Penguin Books, 2002. New York: Simon \& Schuster; 2002.

[7] Hoffrage U, Gigerenzer G. Using natural frequencies to improve diagnostic inferences. Acad Med 1998;73(5):538-40.

[8] Wells HG. World brain. London: Cambridge University Press; 1994. Original work published in 1938.

[9] Charles C, Gafni A, Whelan T. Shared decision-making in the medical encounter: What does it mean? (or, It takes at least two to tango). Social Science and Medicine 1997:44:681-92. 